\title{
OS LIVROS E A NOITE
}

João Carlos Salles

$(U F B A)^{1}$

Estamos no fio da navalha: esse é o nosso mote nesta fala. Instados a prosseguir, obrigados a prosseguir, desejosos de prosseguir (e agora inclusive com condições bem mais favoráveis para um bom trabalho filosófico), sem que, por isso, estejamos protegidos de antigas ameaças, como a irrelevância e o provincianismo. ${ }^{2}$

Primeiro, nunca tivemos à mão tantos recursos bibliográficos. A crônica deficiência de nossas "bibliotecas" é hoje facilmente contornada pelo acesso a livros e artigos pela internet, comprados ou não. Somente seres jurássicos lembram ainda do sacrifício do COMUT ou do elevado custo da importação de livros. ${ }^{3}$ Livros impressos ou eletrônicos, a infinidade de arquivos (pdfs, djvus, epubs), tudo isso afastou-nos a pregressa indigência bibliográfica, que nos

1 Professor do Departamento de Filosofia da UFBA, desenvolvendo pesquisa com bolsa do CNPq e apoio da FAPESB.

2 Em meio à organização do XVII Congresso Interamericano de Filosofia, não tive tempo de preparar um texto. Tampouco poderia recusar o convite de meu amigo Ivan Domingues para participar da mesa sobre Filosofia no Brasil, sendo ademais uma honra estar em sua companhia e na de Vinicius de Figueiredo, Paulo Margutti, Guido de Almeida e Marilena Chauí. Infelizmente, a gravação da mesa atrasou e só tenho transcrita parte da minha fala. Para completar, na azáfama do último dia do Congresso, perdi minhas anotações. Assim, o texto atual, apoiando-se em minha frágil memória, procura não avançar nem divergir da apresentação, mas não pode coincidir com ela, procurando apenas sintetizar alguns pontos, antes apresentados, ao que lembro, com bem mais vivacidade. Certamente, estou me repetindo, se tenho em conta textos anteriores sobre Filosofia no Brasil. Por sinal, inclusive à luz da experiência atual como coordenador adjunto da área de Filosofia na CAPES, creio que mantenho, no essencial, as posições já defendidas no texto "Notas sobre a Filosofia no Brasil", publicado na Revista Cult, São Paulo, pp. 71-73, 1 o out. 2010.

3 Lembro-me de ter mencionado, na fala, a dificuldade constante tempos atrás para a aquisição de livros, exemplificando com uma dispendiosa encomenda feita em conjunto por mim e por Ubirajara Rebouças a uma livraria na França, no início dos anos 80 . Então, certamente na esteira da celebridade de Marilena e da tradução de Giannotti de "O visível e o invisível" (esta, de 1971), a minha parte da encomenda se concentrava em livros de Merleau-Ponty. A danação foi terem vindo no grande pacote alguns livros de Wittgenstein. 
diminuía frente aos grandes centros e nos cindia mais fundamente em regiões desigualmente servidas por laboratórios, em nosso caso, por bibliotecas com o mínimo de edições bem cuidadas de obras clássicas e suficiente acervo contemporâneo, bem como por repertórios completos dos melhores periódicos. Hoje, com tais recursos e, especialmente, com o portal de periódicos da CAPES, saímos quase bruscamente da escassez para a fartura, o que todavia não nos livra por si da ameaça de termos todo esse material, sem que livros e artigos sejam bem lidos ou tenhamos cultivado o hábito de um mínimo de leitura recíproca ou que nossa produção, agora munida de múltiplas e atuais referências, deixe de ser de ocasião (ou de eventos) e adquira relevância.

Temos hoje disponível todo um conjunto de textos, que a pressão das agências (a competição por recursos e posições, segundo o novo modus operandi das áreas mais duras) nos leva contudo a ler limitada e profissionalmente, de sorte que perdemos não só a capacidade de nos lermos, mas mesmo de saborear o legado da Filosofia, de ler com abundância, com olhos precisos e inocentes, aquilo que nos pode despertar a reflexão e o autêntico trabalho conceitual, para o qual a comunidade foi se preparando ao longo das últimas décadas. Com isso, nosso trabalho, ganhando por vezes em refinamento técnico e em fundamentação, corre o risco de crescer também em previsibilidade. No fio da navalha, esperamos ainda poder afastar situação semelhante à que Borges, tendo ficado cego e sendo diretor da Biblioteca Nacional, descreveu como ironia divina, mas que também, por analogia, podemos pensar como tragédia ou farsa: "Ninguém rebaixe a lágrima ou rejeite / Esta declaração da maestria / De Deus, que com magnífica ironia / Deu-me a um só tempo os livros e a noite."4

Segundo, a área de Filosofia cresceu de modo significativo, diminuindo a disparidade regional em aspecto decisivo, qual seja, a formação do corpo docente de nossos Departamentos. A Filosofia consolidou-se como atividade profissional em todo país, conjurando projetos de pesquisa, na condição ora própria da vida universitária. Temos hoje, nas mais diversas regiões, Departamentos compostos por docentes com titulação plena, formados segundo padrões elevados e próprios da área de Filosofia, de modo que, por isso mesmo, a pós-graduação teve extraordinário crescimento, saindo dos cerca de 12 programas na década de 1980 para os atuais 41 programas de pósgraduação, grande parte com mestrado e doutorado. Apesar disso, nossa área não parece ter adquirido força suficiente para impor suas próprias medidas,

4 BORGES, J. L. "Poema dos dons". In: O fazedor. Obras Completas. São Paulo: Ed. Globo, 2000. Vol. II, p. 207. 
a ponto de produtos característicos da melhor produção filosófica, como os livros, se verem depreciados em nossas instituições universitárias, sendo por vezes internalizada em nossa própria área a pura e simples supervalorização da publicação em periódicos.

Periódicos decerto devem ser valorizados, e devemos mesmo recomendar um cuidado especial para toda a área de Filosofia (qualquer a corrente ou metodologia), devendo sua produção ser mais dirigida em quantidade e qualidade a periódicos bem classificados, como de resto é feito nos melhores centros. Indesejáveis seriam sim a multiplicação, a fragmentação e mesmo a automática valorização de instrumentos que, como o Qualis, passaram a ser tomados, contra toda a orientação da CAPES, como medidas absolutas da qualidade de pessoas, sendo usados em concursos, seleções e mesmo na concessão de bolsas de iniciação científica, quando deveriam servir tão somente para a avaliação de programas, como indicação do lócus natural e elemento facilitador da avaliação de parte de sua produção intelectual. Nossa área, porém, cresceu, passou a disputar também recursos e projetos de monta, tendo abandonado práticas menos profissionais, nas quais o prestígio intelectual não precisava ser testado segundo medidas públicas, não se medindo outrora o valor da argúcia intelectual pelos argumentos impressos. O risco, porém, ao abraçarmos manifestações exteriores de riqueza intelectual e utilizarmos tais medidas para nossa avaliação, é encontramos outras formas de prestígio artificial, outros mecanismos de simples poder, e de, ao abandonarmos o amadorismo, jogarmos a criança fora com a água suja do banho.

Terceiro, nossa comunidade jamais conheceu tamanho intercâmbio ou foi beneficiada por tantos recursos para a pesquisa e também para eventos. Os eventos há muito deixaram de ser raios em céu azul. Os projetos de intercâmbio, por sua feita, deixaram de ser prerrogativa de uns poucos centros. Ao contrário, são tantos e tão frequentes eventos e projetos, que chegamos sim a temer a abundância, a patente repetição, sem que instrumentos de cooperação sejam aproveitados com a devida profundidade ou que, nos casos dos eventos, a cooperação não se mostre, em todos os casos, mais importante que o mero turismo. Os benefícios de cooperações e eventos, todavia, são muito superiores aos desvios, que são de somenos importância. Nesse sentido, para a realização de tantos eventos, no que têm de melhor e no decisivo que têm sido para a criação de uma comunidade nacional, não podemos deixar de enfatizar o papel da ANPOF. Tanto na realização como na divulgação de eventos, a ANPOF tem favorecido o intercâmbio nacional e agora, como associação membro da SIF, favorece o intercâmbio internacional, como bem o 
exemplifica este Congresso Interamericano, no qual, aliás, dos 1000 trabalhos apresentados, mais de 350 o são por estrangeiros. ${ }^{5}$

Esse contexto, que nos faz dialogar com uma extensa produção estrangeira e que, por sinal, mais e mais, se dá em inglês, não pode ser ocasião ou pretexto para abandonarmos a tarefa histórica de firmar o português como uma língua propícia à mais elevada atividade filosófica, tanto por encontrarmos nela expressão adequada para as mais refinadas distinções conceituais, como por realizarmos nela debates em conformidade com as mais rigorosas exigências internacionais, lembrando porém que, por nossa história e pela natureza do trabalho de qualidade em Filosofia, nós, brasileiros, sempre precisamos ser ao menos bilíngues (ou, no dizer agressivo de um colega, analfabetos em muitas línguas). E aqui, também no fio da navalha, cumpre evitar o provincianismo de nos fecharmos em nossa própria língua, recusando um debate na forma e nos meios em que se dá internacionalmente; provincianismo cujo absurdo só tem correlato neste outro, o de abandonar servilmente a expressão em língua portuguesa, em favor de uma inserção subordinada em periódicos de língua inglesa. ${ }^{6}$ Provincianismos desses tipos costumam aliás ser parceiros da intolerância epistemológica, quer para impor a procedimentos e temas que nos são estranhos, quer para sufocar procedimentos que não sejam ditados por modismos internacionais. Em suma, o problema não nos parece ser a língua, mas sim se seremos pautados por interesses pontuais ou menores, condenados a notas de rodapé no debate internacional, sendo pautados ou não por programas de investigação um tanto unilaterais e bastante estranhos a nosso repertório de questões, que assim não rebatem em uma tradição mais ampla, da qual nos preparamos para fazer parte, sobretudo pelo grande investimento de nossa pós-graduação, que tem cultivado um repertório extenso de questões e formas diversas para um trabalho de qualidade em Filosofia.

Em todas essas dimensões, cabe procurar o justo meio entre o deslumbramento e a cegueira, entre o desdém de medidas externas ou sua simples valorização, mas também entre a mera valorização da interioridade e profundidade do fazer filosófico ou seu desdém, pois tal medida interior, afinal, por intangível que seja, não deixa de se expressar nos diálogos que trava e nas pessoas que vem a formar; e assim, mesmo se mal conseguimos enunciála, nós a reconhecemos deveras, misteriosamente, como o bom jogador pelo

5 Com minha eleição para a presidência da Sociedade Interamericana de Filosofia, o Brasil passou a ser a sede da SIF até a realização do próximo Congresso.

6 Recomendo enfaticamente, sobretudo a quantos não acompanharam debates antigos sobre o ensino de latim e francês no ensino médio, bem como a quantos apreciem o aprendizado de línguas, o belo livro de RÓNAI, P. "Como aprendi o português e outras aventuras". Rio de Janeiro: Casa da Palavra, 2013. 
arriar das malas. Enfim, procurando esse justo meio e evitando os caminhos fáceis da intolerância e do artifício, nossa comunidade filosófica, tendo já avançado muito em sua integração nacional, deve agora, para afirmar-se em relação a outras áreas do saber e também para firmar-se internacionalmente, continuar combatendo a "síndrome de Virchow", que resumimos aqui, ao tempo que concluímos.

Em um texto antigo, batizamos a síndrome por uma anedota de Rudolf Virchow, temível arguidor em exames orais de Medicina e célebre por sua coragem inclusive na oposição a Bismarck. Não obstante sua consabida rigidez, Virchow considerou correta em um exame final a resposta absurda do príncipe do Sião (verdadeira anta, incapaz de fazer um 'o' com um copo), pretextando que, antes da arguição, o senhor príncipe prometera que jamais exerceria a medicina na Alemanha. ${ }^{7}$ Cabe assim combater a síndrome, ou seja, criar e renovar as condições para que nossas dissertações e teses sejam comensuráveis entre nossos programas, partilhando medidas elevadas de qualidade e interesse com os melhores centros internacionais. Da mesma forma, cabe criar e renovar condições para que a presença crescente de pesquisadores estrangeiros no Brasil e nossa também crescente presença em centros internacionais signifiquem uma autêntica cooperação acadêmica. Enfim, combater a "síndrome de Virchow" é esse exercício que fazemos conjuntamente, ou seja, empregando medidas comuns de qualidade e talento filosófico, evitando que medidas não maturadas, simplesmente por valerem para os grandes centros, passem a dominar nossa língua ou nosso modo de pensar. Que nossas medidas e nosso trabalho também possam trazer uma contribuição para a Filosofia; e aí, sim, acredito, a Filosofia no Brasil poderá colocar sua colher torta no belo legado de nossa tradição e nas questões que ora nos desafiam. 